Luca Fazzini*

Universidade de São Paulo

\title{
Visões de Lisboa em dissonância: dinâmicas do poder no espaço urbano e escritas em trânsito
}

Resumo:

O presente artigo propõe uma reflexão em torno das escritas produzidas na Europa e, em particular, em Portugal, por sujeitos em trânsito, migrantes contemporâneos, evidenciando as dissonâncias presentes nesses textos em relação ao imaginário coletivo hegemônico, e suas possíveis contribuições. Tendo como objeto de análise as dinâmicas urbanas e a ação do poder público na cidade de Lisboa, assim como a representação do espaço lisboeta por experiências literárias contemporâneas - dentro das quais destaca-se o romance Luanda, Lisboa, Paraíso (2018), de Djaimilia Pereira de Almeida - esse artigo evidencia a articulação entre o desenvolvimento do capitalismo na contemporaneidade e as persistências coloniais no cotidiano urbano da cidade de Lisboa.

Palavras-chave:

Estudos pós-coloniais, Literatura contemporânea, Literatura Afro-Portuguesa

\section{Abstract:}

This article aims to analyse the literature produced in Europe and in Portugal in particular, by people in transit, contemporary migrants, focusing on the dissonances present in these texts in relation to the hegemonic collective imaginary. Considering the urban dynamics and the action of public power in Lisbon, as well as the representation of the city space in contemporary literary texts - including the novel Luanda, Lisboa, Paraíso (2018), by Djaimilia Pereira de Almeida -, this article highlights the relationship between contemporary capitalist development and colonial persistence in the daily life of the city of Lisbon.

Keywords:

Post-colonial studies, Contemporary literature, Afro-Portuguese Literature 


\section{Introdução: escritas itinerantes como contrapontos}

Uma antiga praça, no coração de uma capital do sul da Europa, outrora metrópole de um vasto império colonial. Cercada por prédios, alguns dos quais modernos, as geometrias do espaço abrigam o fluxo da multidão em trânsito. As águas das fontes - uma constante nas praças do velho continente - jorram sem parar, amenizando o sol quente do verão. Entre um jato e um outro, crianças dançam, fazem piruetas e viravoltas, fingem mergulhos como em lembranças de praias distantes. A juventude, vital e alegre, contrasta com a paisagem cinzenta ao redor. Os corpos, diversos, acompanhados pelas músicas de Luiz Gonzaga entoadas por Caetano Veloso, irrompem na cena.

Trata-se de uma das poucas imagens vivas e desinibidas do filme Lisboetas (2004), do diretor Sérgio Tréfaut. O documentário acompanha a experiência migrante, marcada por violências e exploração, de várias comunidades espalhadas pela cidade de Lisboa. Em contraste com as experiências dos corpos que a habitam, a praça na qual se passa a cena descrita reativa memórias míticas ligadas à identidade nacional, homenageando Martim Moniz, o herói do Cerco de Lisboa (1147), no âmbito da Reconquista da Península Ibérica. Segundo a lenda, o cavaleiro sacrificou-se pela vitória cristã, morrendo entalado entre as portas do Castelo de São Jorge, permitindo dessa forma a invasão da cidadela pelas tropas do rei D. Afonso Henriques.

Indiferentes às configurações sociais urbanas, sempre mais globais, os espaços das metrópoles contemporâneas desdobram-se no mapa como complexos de memórias. Monumentos, praças, ruas e avenidas inscrevem o passado mítico, ocidental-cristão, no cotidiano urbano, reatualizando as próprias narrativas centrípetas no vaivém do dia a dia. Na contemporaneidade pós-colonial e global, existe um hiato sempre mais patente entre o imaginário simbólico produzido pelas memórias míticas do passado e as vivências dos sujeitos que coabitam esses espaços: acompanhando os tantos trânsitos de um mundo de fluxos, outros "infiéis" dos outrora derrotados pelo sacrifício do mártir Martim Moniz ressignificam hoje os lugares, inscrevendo neles, embora que de forma subalterna, a experiências dos seus corpos e de suas culturas - línguas, religiões, tradições Outras - no coração da antiga metrópole. São os lisboetas que Sérgio Tréfaut elege como protagonistas da sua visão da cidade de Lisboa, oriundos do continente africano, da Ásia, do Oriente Médio e das margens europeias. Sujeitos em constante movimento: dentro da cidade - em Lisboetas, nas tantas imagens no interior de transportes coletivos - , e através das fronteiras porosas que dividem os Estados-Nação: se há alguém que mais que qualquer outro conheça de forma orgânica a complexidade do mundo globalizado e as suas múltiplas geografias são justamente esses indivíduos, os migrantes, ou errants contemporâneos, retomando a definição de Étienne Balibar (2019). São eles que atravessam o globo por rotas carregadas de arbitrária violência, que habitam as periferias das metrópoles ocidentais, enquanto, ao mesmo tempo, trabalham de forma precária e sempre subalterna nos centros pulsantes de capital financeiro e de memórias míticas fixadas nos mármores.

Perante a intensidade desses fluxos, as políticas de exclusão social que desenham a "vida descartada" desses "sujeitos almejantes" (Butler/Spivak 2018) como uma ameaça no interior de uma comunidade que se quer homogênea, assim como as práticas de exclusão cultural que, 
em diversos níveis, inibem a participação desses atores à construção de memórias e identidades coletivas, parecem empreitadas falhas, comparáveis à construção da Muralha pelo Imperador da China, assim como descrita em dois contos de Franz Kafka, ${ }^{1}$ discutidos por Péter Pal Pelbart:

O Imperador da China resolveu, um belo dia, construir uma Muralha que contornasse a imensidão do Império e o protegesse contra a invasão dos nômades vindos do Norte. A construção da Muralha mobilizou a população inteira por anos a fio. Conta Kafka que ela foi empreendida por partes: um bloco de pedra era erguido aqui, outro ali, mais um acolá, e não necessariamente eles se encontravam [...]. 0 resultado foi uma muralha descontínua cuja lógica ninguém entendia, já que ela não protegia de nada nem de ninguém. Talvez apenas os nômades, na sua circulação errática pelas fronteiras do Império, tinham alguma noção do conjunto da obra. No entanto, todos supunham que a construção obedecesse a um plano rigoroso elaborado pelo Comando Supremo, mas ninguém sabia quem dele fazia parte e quais seus verdadeiros desígnios. Enquanto isso, um sapateiro residente em Pequim relatou que já havia nômades acampados na praça central, a céu aberto, diante do Palácio Imperial, e que seu número aumentava a cada dia. (2011: 19)

Em termos culturais, qualquer reflexão em torno da arte e da literatura contemporânea não pode, de fato, ignorar a contribuição desses sujeitos em trânsito, nômades ou migrantes da atualidade. Suas experiências globais, disseminadas em múltiplos espaços, demandam uma abordagem descentrada que ultrapasse, a priori, qualquer vínculo com uma suposta origem nacional, pois se desenvolvem justamente na fronteira entre diversas geografias, culturas e tradições, levantando questões de caráter pós-colonial, como a crítica ao eurocentrismo dominante tanto na produção de cânones nacionais ou transnacionais, tanto nas construções teóricas e estético-formais a partir das quais são pensadas a arte e a literatura.

Tal urgência é evidenciada por Armando Gnisci no seu Creolizzare l'Europa: letteratura e migrazione. Para o comparatista italiano, a experiência da literatura pós-colonial, entendida no sentido mais amplo do termo, incluindo, portanto, todas aquelas escritas que a partir da crítica ao colonialismo - as suas múltiplas formas de violência política, militar, cultural e epistêmica - abalaram as estruturas eurocêntricas do pensamento, demanda uma diferente conceptualização daquilo que, retomando expressamente Goethe, chama de Weltliteratur, ou Literatura Mundial:

La letteratura mondiale non è più il sistema di valori estetici e culturali europei proiettati più o meno surrettiziamente sul mondo ma è la dimensione concreta della produzione, ricezione e studio letterario oggi. Lo scrittore e lo studioso che sta fuori di queste coordinate finalmente generali bisogna che si rieduchi o toccia. Insomma, voglio affermare che: l'unica teoria e metodologia proponibili negli studi interculturali - letterari e non - consistono nel preliminare e specifico apprezzamento del grado storico e personale di coinvolgimento e di conoscenza dei partner epistemici in gioco. E il gioco, oggi, é quello più generale che sia mais stato giocato nel corso dell'umanità. (Gnisci 2003: 25) 
Cadernos de Literatura Comparada

Visões de Lisboa em dissonância

[A literatura mundial não é mais o sistema de valores estéticos e culturais europeus projetados mais ou menos sub-repticiamente no mundo, mas é a dimensão concreta da produção, recepção e estudo literários hoje. $\mathrm{O}$ escritor e o estudioso que estão fora dessas coordenadas finalmente gerais devem ser reeducados ou tocados. Em suma, quero afirmar que: a única teoria e metodologia que pode ser proposta nos estudos interculturais - literários e não literários - consiste na apreciação preliminar e específica do grau histórico e pessoal de envolvimento e conhecimento dos parceiros epistêmicos em jogo. E o jogo, hoje, é o mais geral que já foi jogado no curso da humanidade].

Nessa sua reconfiguração epistemológica dos estudos literários e culturais, mais voltada para o universo crítico e teórico decolonial que para o atual interesse em torno da Literatura Mundo/Literatura Mundial, Armando Gnisci debruça-se sobre aquilo que ele mesmo define como literatura da migração (Letteratura della Migrazione), ou seja, uma literatura escrita por sujeitos de alguma forma marcados pela experiência do deslocamento, do escrever na língua do Outro. Uma língua que pode ser tanto uma língua nova, propiciada pela vivência em terras distantes, nas tensões entre conquistas simbólicas e perdas caraterísticas dos processos de desterritorialização - como destaca Silviano Santiago na sua bela e sensível análise do filme Viagem ao Princípio do Mundo (1997), de Manoel de Oliveira, em "O cosmopolitismo do pobre" (2004) -, tanto a língua imposta pelo domínio colonial, criando uma estrita proximidade entre a literatura da migração e as escritas pós-coloniais.

Em termos meramente literários, ler tais textos e tais autores permitiria subverter os topoi de grande parte da tradição literária ocidental. Veja-se, apenas como exemplo, a temática da viagem: já não do Norte ao Sul, acompanhando as rotas dos exploradores ocidentais - a do Vasco da Gama em Os Lusíadas (1572), apenas para permanecer no universo literário em português - , e os seus contatos com o Outro, mas do Sul rumo ao Norte, desenhando os fluxos e as inserções subalternas nas dinâmicas contemporâneas da "aldeia global". Temática, a da viagem, presente em diferentes tradições literárias ocidentais, frequentemente vinculada à construção de narrativas míticas de teor heroico sobre o papel social da colonização e, mais tarde, do capitalismo. No primeiro capítulo de Il Borghese. Tra storia e letteratura (2017), Franco Moretti lê as viagens de Robinson Crusoe a partir de algumas palavras-chave necessárias para entender aquilo que é, de fato, um grande mito moderno delineado pelo romance europeu dos séculos XVII e XIX, ou seja, o do capitalista aventureiro, burguês, cuja coragem vai além dos riscos intrínsecos aos empreendimentos em terras distantes e cuja ética do trabalho o diferencia dos conquistadores coloniais, violentos e irracionais. As palavras-chave propostas por Moretti, amparadas nas reflexões de Max Weber em A ética protestante (1905), são emblemáticas para pensar a construção literária desse tipo social: aventura, utilidade, eficiência e comfort. O espaço do Outro - no caso do romance de Defoe, a ilha - é, portanto, um lugar funcional para a exaltação das caraterísticas da figura hegemônica da modernidade capitalista: "l'isola offre il primo scorcio del padrone industrioso dei tempi moderni; il mare, l'Africa, il Brasile; Venerdí e le altre aventure danno você alle forme più antiche - ma mai del tutto abbandonate - del domínio capitalista [a ilha oferece o primeiro vislumbre do mestre trabalhador dos tempos modernos; o mar, a África, o Brasil; Sexta-feira e as 
outras aventuras dão voz às formas mais antigas - mas nunca completamente abandonadas - do domínio capitalista] (Moretti 2017: 30).

Diversamente, o reverso dessas viagens encenado pelas escritas migrantes examinadas por Armando Gnisci revela uma realidade cuja única peripécia é a sobrevivência num território hostil - a Europa para os não europeus -, onde não há utilidade nem eficiência, mas apenas processos de reificação, instrumentalização e desumanização que passam pela transformação do sujeito migrante em Outro ontológico, como se pode ler no romance Immigrato do escritor originário da Tunísia Salah Methnani, escrito em italiano e publicado em 1990:

Sono costretto a non vedermi più, in così poco tempo, come un giovane laureato all'estero. Non sono già più un ragazzo che vuole viaggiare e conoscere. No: di colpo, mi scopro a essere in tutto e per tutto un immigrato nordafricano, senza lavoro, senza casa, clandestino. Un individuo di ventisette anni venuto qui alla ricerca di qualcosa di confuso: il mito dell'Occidente, del benessere, di una specie di libertà. Tutte parole che già stanno incominciando a sfaldarsi nella mia testa. (apud Gnisci 2003: 29)

[Sou obrigado a não mais me ver, em tão pouco tempo, como um jovem graduado no exterior. Não sou mais um menino que quer viajar e conhecer. Não: de repente, me vejo em todos os aspectos um imigrante norte-africano, desempregado, sem teto, ilegal. Um jovem de 27 anos que veio aqui em busca de algo confuso: o mito do Ocidente, do bem-estar, de uma espécie de liberdade. Todas as palavras que já estão começando a desmoronar na minha cabeça]. (apud Gnisci 2003: 29)

Interrogar essas escritas, se, por um lado, levanta outras possibilidades de percepção do real, outras formas de estar juntos e de pensar a comunidade - em Creolizzare l'Europa: letteratura e migrazione, o crítico destaca as diferentes concepções do encontro e da hospitalidade proporcionadas pelo contato com textos escritos por autores oriundos do Norte da África -, por outro lado, a intrínseca denúncia da violência ordinária e das micropolíticas de exclusão cotidiana conserva uma forte carga política de subversão das narrativas dominantes. Narrativas sustentadas não apenas pela literatura, mas por todo um conjunto de dispositivos e práticas que envolvem, entre outros, as políticas públicas, a ação do mercado e a produção cultural.

Tendo em consideração a complexidade e a multiplicidade dessa produção de discursos legitimadores das perspectivas do poder, investigar o alcance político de certas escritas demanda uma abordagem transversal e interdisciplinar, que não fique restrita apenas ao campo literário. Com esse pressuposto, a partir de um olhar voltado para as relações conflituais e as tensões sociais subjacentes à "paisagem étnica" (ethnoscape)2 (Appadurai 1991) da cidade de Lisboa, pretende-se evidenciar, com essas páginas, as persistências das dinâmicas coloniais subjacentes à construção e reificação da diferença racializada na capital lusitana, assim como a inserção de certos autores e certas escritas - com particular atenção pelo romance Luanda, Lisboa, Paraíso (2018), de Djaimilia Pereira de Almeida - no panorama cultural lisboeta, enquanto contrapontos dissonantes em relação às ações do poder. 
Cadernos de Literatura Comparada

Visões de Lisboa em dissonância

\section{Lisboa: marketing cosmopolita no centro urbano e persistências coloniais contemporâneas}

Andar pelas ruas de cidades como Lisboa, significa cruzar-se com inúmeras praças, palácios e jardins repletos, ainda hoje, de referências que remetem diretamente para as longínquas geografias de um passado colonialista. Memórias disseminadas também na toponímia dos lugares, como no caso, entre outros, do Bairro das Colonias, um bairro em Art Decó composto por ruas com o nome das antigas colónias, construido entre a década de 20 e a de 30 para celebrar a vastidão do império. Ou como o emblemático bairro de Belém, sempre na capital portuguesa, verdadeiro espaço de sinalização pública da identidade nacional. Citando Elsa Peralta:

As paisagens urbanas europeias são paisagens saturadas de produtos da memória coletiva: sítios patrimoniais, museus, placas comemorativas, lugares monumentais. Lugar-fétiche da modernidade, a cidade torna-se um espaço retrospetivamente definido com base nas ideologias sacralizadas dos passados regionais ou nacionais, enquanto, simultaneamente, se presentifica como o lugar de avant-garde do processo científico e tecnológico, da indústria e do consumo. Aí são criadas formas materiais e técnicas de oficialização de uma memória coletiva, desenhadas para simbolizar a unidade nacional e para legitimar o controlo administrativo do Estado, bem como a sua inserção no sistema-mundo capitalista. (2013: 362)

No que diz respeito à cidade de Lisboa, para além do espaço urbano, o passado colonial deixou marcas evidentes também no plano social e demográfico, pois seja durante a época colonial, seja após as independência dos países africanos, a cidade recebeu um enorme fluxo de indivíduos provenientes de todos os cantos do mundo, acompanhando as rotas da desigualdade erigidas pelo colonialismo e pelos paradigmas excludentes moldados durante a modernidade ocidental - perpetrados sem interrupções nem roturas na contemporaneidade global. De acordo com Miguel Vale de Almeida, no artigo "Comentário", publicado na coletânea Portugal não é um país pequeno: contar o império na pós-colonialidade, organizada por Manuela Ribeiro Sanches:

quando os africanos pós-coloniais migraram para Portugal, migraram para ocupar posições de classe que lhes retiram toda e qualquer mais-valia enquanto exóticos localizados. Ocupam agora as margens do centro, nas relações de produção, como na geografia social. Dos indígenas coloniais preservam (é-lhes preservado) o trabalho compulsório; como o são as 'raízes' da sua indigeneidade, sob a forma de expressões culturais diferenciadoras. A indigeneidade, agora glosada como nacionalidade, aquilo que os torna em estrangeiros, é o que lhes veda o acesso à cidadania. O que se lhes exige como saída é a assimilação, agora glosada como integração. (2006: 367)

No entanto, ao investigar as formas de inscrição subalterna dos migrantes contemporâneos e dos filhos destes, assim como a ação do poder sobre os corpos e em termos de gestão e capitalização da diferença, limitar o campo de análise impõe-se como necessário. De fato, assim como em outras metrópoles, a ação do poder diferencia-se de acordo com as geografias 
urbanas: se nas periferias lisboetas - lugares nos quais a presença de sujeitos originários das ex-colônias é sem dúvida marcante - assiste-se à ação violenta das instituições com intuito repressivo, à precariedade habitacional, à falta dos direitos básicos de cidadania e invisibilização social, ${ }^{3}$ no centro da capital e nas suas áreas historicamente "marginalizadas", as políticas de gentrificação que investem na diversidade cultural escondem dinâmicas e paradigmas igualmente violentos. É o caso, entre outros, dos bairros situados ao redor da praça Martim Moniz e ao longo da Avenida Almirante Reis, uma área urbana historicamente multicultural, que passou, na última década, por importantes investimentos. Observar a ação do poder nesse espaço urbano torna-se particularmente relevante, pois nele articulam-se estratégias e discursos de caráter "pós-luso-tropical", para usar uma expressão de Miguel Vale de Almeida (2000), que silencia e pacifica as tensões existentes, visando capitalizar a diferença étnico-racial.

Acompanhando os fluxos das migrações globais, tais bairros "periféricos" do centro de Lisboa receberam, ao longo do século XX, imigrantes provenientes de todos os cantos do mundo, influenciando também o imaginário coletivo: "a etnização crescente tornou-se parte não apenas da sua composição social como também das percepções que dela têm os cidadãos de Lisboa e os seus visitantes" (Oliveira 2013: 572). No entanto, é necessário também lembrar que o bairro da Mouraria, que se insere no coração desse eixo espacial que vai da Praça da Figueira até ao Bairro das Colónias, foi sempre abrigo de populações deslocadas, pois além de ter sido designado, ainda em 1147, com o nome de Mouraria, justamente por ser, na época, um ghetto árabe e muçulmano, foi também o lugar onde se estabeleceu grande parte da população rural de Portugal, que se mudava para a capital à procura de melhores condições econômicas e de ascensão social.

Ao longo dos séculos, a expansão dos fluxos migratórios em escala global fizeram com que também os bairros adjacentes se tornassem profundamente multiculturais, abrangendo uma população proveniente de todos os cantos do mundo. Como relata Jorge Macaísta Malheiros em Imigrantes na região de Lisboa: os anos da mudança (1997), em um primeiro momento, essa área do centro histórico lisboeta recebeu populações oriundas do subcontinente indiano, aos quais se seguiram os africanos e, nas últimas décadas do século XX, chineses, eslavos, brasileiros e bangladeshianos (Malheiros 1997).

Em seu artigo "Um lugar estrutural? Legados coloniais e migrações globais numa rua em Lisboa" (2013), José Mapril analisa as mudanças tanto na geografia urbana quanto na social que atingiram os bairros adjacentes à Mouraria, a partir do estudo de uma das principais artérias que cruza tais bairros: a Rua do Benformoso, uma rua que liga a Praça do Martim Moniz ao Largo do Intendente, conjugando-se, na outra extremidade do largo, com a Rua dos Anjos. O autor sublinha como, desde 1900, essa área da cidade sofreu com numerosos e inacabados processos de renovação urbanística. As medidas propostas pela Câmara Municipal de Lisboa, além de visarem uma alteração das dinâmicas sociais e culturais existentes, "procuravam também higienizar e embelezar uma zona cuja imagem tinha sido construída ao longo de décadas como "problemática e ameaçadora em relação aos valores normativos da classe dominante" (Mapril 2013: 511). o paradigma da salubridade moldou, de fato, uma primeira fase de intervenção "higienizadora" 
operada ainda durante o Estado Novo como parte de um "projeto mais vasto de 'urbanismo civilizador' como forma de domesticar um bairro popular impondo-lhe um ordenamento urbano à imagem da estética de Le Corbusier" (Oliveira 2013: 577).

Consequência direta das tantas demolições - que chegaram a atingir, em 1949, também o Mercado Central de Lisboa, antigamente situado na Praça da Figueira - e da falta de investimentos posteriores, foi a contínua desvalorização financeira do bairro, a qual veio a se somar à marginalização econômica da Av. Almirante Reis em relação aos outros centros tradicionais de comércio da cidade, como Av. da Liberdade, Av. Fontes Pereira de Melo e Av. da República (Mapril 2013). É nesse contexto que o eixo urbano em análise, historicamente ocupado por uma população diaspórica, assistiu à progressiva implantação de pequenos comércios como quiosques e lojinhas de revenda, geridos por imigrantes provenientes principalmente da Ásia e da África. Os primeiros, em maioria indianos e chineses, passaram a vender sobretudo brinquedos, bijuterias e mobiliário, enquanto os segundos, frequentemente oriundos de Angola, Guiné-Bissau e Senegal, concentraram os seus negócios na área da música, da alimentação e da restauração. De acordo com José Mapril:

Uma parte das migrações contemporâneas que chegaram a Portugal através de processos relacionados com as dinâmicas globais das migrações parece ter vindo a ocupar o mesmo lugar, também estrutural, anteriormente ocupado por migrantes oriundos de contextos coloniais portugueses. Neste sentido, parece-me pertinente sugerir que existem evidentes continuidades entre legados coloniais, o lugar de determinados segmentos da imigração e a produção de margens na sociedade portuguesa contemporânea. (2013: 506)

Mais recentemente, tal diversidade cultural concentrada numa das áreas mais centrais da capital lusitana motivou, a partir do ano de 2010, a implementação de uma série de reformas, atividades e eventos por parte da Câmara Municipal de Lisboa, com o apoio do empreendedorismo privado. Como sugere Nuno Oliveira em "Lisboa Redescobre-se: a governança da diversidade na cidade pós-colonial" (2013), das intervenções realizadas podem ser destacados os seguintes elementos:

Preparação do território para a alocação de indústrias da cultura ou ligadas à produção criativa acompanhada de uma forte aposta em atividades culturais com a ocupação do espaço público; atração de gentrifier como forma de recomposição do tecido social do bairro; turismo criativo e busca da autenticidade; e finalmente, a interculturalidade endógena ao bairro como fator de atração tantos de turistas como de potenciais "diversity seekers". (Oliveira 2013: 582)

A "gestão da diferença", operada pelo poder em áreas urbanas tradicionalmente estigmatizadas, com a "exotização" do Outro e a construção de um branding lisboeta cujo leitmotiv é a diversidade, reproduz justamente a reificação do Outro que marcou a modernidade colonial. Ao aniquilamento ou à escravização do Outro operada pelo colonialismo, substitui-se hoje a patri- 
monialização, a estetização e a exploração da imagem que as presenças "exóticas" oferecem à cidade. Cidade que pretende ser a "encruzilhada de mundos", nome de um gabinete da Câmara Municipal de Lisboa-Gabinete Lisboa Encruzilhada de Mundos (GLEM), responsável pela organização de festivais de caráter multicultural. No entanto, apesar de ter sido camuflado pela retórica da revitalização e da renovação da área urbana, esse processo de constante glamourização da diferença trouxe consigo a violência intrínseca às "modernizações". O destino das pequenas atividades comerciais situadas no Martim Moniz, tradicionalmente geridas por populações migrantes aparece como simbólico da atuação do poder:

Dos 44 quiosques outrora existentes no final da década de 1990, nenhum sobreviveu e os novos espaços comerciais foram concessionados a projetos diferenciados de restauração com a condição de cada um representar uma nação em particular, seguindo desta maneira o 'imperativo do aproveitamento' [...]. Estas iniciativas configuram a materialização do ethnic chic, ou seja, o étnico comercializável: lojas como a Embaú, Brazilian wearstore, substituem os velhos quiosques onde comercializavam imigrantes residentes na Mouraria. (idem: 587)

A própria narrativa construída pela Câmara Municipal de Lisboa é por si significativa. Os nomes dos locais, renovados pelas ações em conjunto do poder público e do setor privado, assim como os dos eventos, apontam hoje como antigamente para a mesma retórica das viagens, das descobertas e do encontro pacífico entre alteridades. Sem nenhuma referência às violências e aos conflitos subjacentes ao "multiculturalismo lisboeta", o espectro do luso-tropicalismo volta a habitar o imaginário português e a imagem de si que Portugal quer vender, literalmente, para o resto da Europa. A atração dos chamados gentrifiers marginais, ou seja, de uma população "em média jovem, proveniente da classe média e média-baixa com profissões ligadas à economia simbólica ou social cujo ethos conforma-se a um certo cosmopolitismo pós-moderno" (idem: 588), corresponde efetivamente à expulsão de parte da população que ali reside, tanto no que diz respeito à área do comércio e do trabalho, quanto à da moradia, já que após as intervenções do poder tais bairros tornaram-se inacessíveis para grupos - de origem estrangeira, mas não apenas - economicamente mais fracos. De acordo com Nuno Oliveira, "o cosmopolitismo que ali se pretende fomentar é assim, em larga medida, um cosmopolitismo educado, ou seja, é a classe média e média-alta que participa deste cosmopolitismo"(idem, 2013: 589).

Relevante, nesse sentido, é investigar as estratégias através das quais tentaram incrementar os investimentos tanto dos chamados gentrifiers marginais, quanto da classe média. No artigo mencionado, Nuno Oliveira traz como exemplo dessa tentativa de aproximar a classe média ao bairro o FestivalTodos- Caminhada de Culturas, evento associado ao citado Gabinete da CML chamado Lisboa, encruzilhada de mundos. O objetivo do festival era convidar "todos" a conhecer e a visitar a Mouraria e os bairros ao seu redor. A interagir com a população que ali reside. Através da dimensão da experiência do conviver juntos, pretendia-se estabelecer laços de empatia entre os visitantes e os moradores do bairro: 
os fotógrafos tiraram fotografias que juntavam pessoas do bairro com os imigrantes, em registo de relato de família, posteriormente colocadas em locais visíveis tais como as balaustradas de janelas, portas e paredes exteriores ou outdoors publicitários na Praça do Martim Moniz. A mensagem subjacente é a do "ama o teu vizinho como a ti próprio" no pressuposto da construção necessária de um contexto cultural comunitário onde relações de interconhecimento fortaleçam os laços sociais. (idem: 584)

O intuito era claramente o de combater, através da empatia, o medo daquilo que de fato era desconhecido e que tinha conotações negativas relacionadas à violência e à "insalubridade", após ter sido secularmente estigmatizado. O resultado foi o consequente afastamento dos antigos moradores do bairro - com os quais se pretendia, supostamente, conviver e compartilhar o espaço - e a sua substituição por uma classe média que apostasse no cosmopolitismo do lugar sem ser, obrigatoriamente, cosmopolita.

Perante essas dinâmicas de intervenção urbana, que visam domesticar as diferenças com o intuito de produzir mais-valia - a capital produzindo o capital, retomando a ambiguidade semântica da palavra capital proposta por Jacques Derrida no seu ensaio O outro cabo (1995) perpetrando, de fato, a reificação e instrumentalização do Outro caraterística da época colonial, investigar a produção literária de sujeitos marcados por processos diaspóricos ou, mais em geral, de desterritorialização, torna-se particularmente relevante. A partir dessas escritas, desenha-se aquela Lisboa silenciada pelas estratégias de marketing luso-tropical contemporâneo, e cuja contribuição foi sempre marginalizada, dentro dos processos de construção da memória coletiva e do imaginário simbólico e cultural nacional.

\section{Em outras palavras, outra cidade: Luanda, Lisboa, Paraíso (2018), de Djaimilia Pereira de Almeida}

Desde a época moderna, a cidade de Lisboa foi marcada por um enorme fluxo de indivíduos provenientes de todos os cantos do mundo, acompanhando as rotas da desigualdade erigidas pelo colonialismo e perpetradas pelo capitalismo global. No entanto, olhando de forma panorâmica para a produção artística e cultural em volta da antiga metrópole imperial, pelo menos até meados do século XXI, observa-se uma quase completa ausência de toda essa multidão alógena. De acordo com António Pinto Ribeiro:

Lisboa é hoje uma cidade multicultural. À semelhança de outras cidades do interior do país, Lisboa é uma cidade multicultural, embora sem práticas multiculturalistas. [...] Portugal, como aliás toda Europa, já não é um país branco. As migrações e a permanente circulação de pessoas transformaram esse país. No entanto, um fenômeno social escamoteia esta nova realidade sociológica: estas centenas de milhar de "novos lisboetas" (para utilizar a expressão do cineasta Sergio Trèfaut), que alteraram radicalmente a paisagem humana, são, de certo modo invisíveis. (2005: 209)

Hoje em dia há uma relevante produção artística e cultural que permite imaginar Lisboa como sendo uma cidade multicultural. Como discutido no capítulo anterior, algumas dessas 
produções foram inclusive desenvolvidas e patrocinadas diretamente pelo poder público, na tentativa de impor para a cidade uma imagem de capital europeia onde as diversas culturas se encontram e convivem sem conflitos, ressuscitando assim os antigos fantasmas do luso-tropicalismo. Exemplos pertinentes desses processos e dessas estratégias podem ser encontrados também no âmbito da produção literária. É o caso, entre outros, da colaboração literária do escritor angolano José Eduardo Agualusa com a Câmara Municipal de Lisboa, da qual surgiu um "roteiro literário" (Oliveira, 2013: 592) da capital chamado Lisboa, cidade de Exílio: o mundo em Lisboa (1999), mencionado por Nuno Oliveira no artigo já citado. Para Oliveira, no texto de Agualusa vislumbram-se e cruzam-se duas marcas caraterísticas desta redescoberta da multiculturalidade intrínseca à cidade de Lisboa: o desejo luso-tropicalista de querer construir para a capital portuguesa uma identidade essencialmente híbrida, pacificadora dos conflitos, e uma nostalgia melancólica - no sentido dado ao termo por Paul Gilroy (2004) - do império perdido. Como relata Oliveira, isso se torna evidente no capítulo chamado "Lisboa de todas as cores United Colors of Lisbona" - título que retoma abertamente as publicidades multirraciais da Benetton, uma das primeiras marcas a apostar em um imaginário global de consumo baseado na flexibilidade das identidades e dos corpos4:

Num capítulo intitulado Lisboa de todas as cores - United Colors of Lisbon, o escritor elabora uma identidade para a Mouraria, e por decorrência para o resto de Lisboa, que se afirma enquanto cultural e etnicamente híbrida desde os seus primórdios. E para que não restem dúvidas quanto à sua natureza híbrida, o centro comercial surge como metáfora da grandeza imperial perdida. O centro comercial da Mouraria é reputado de lugar de viagem pelos velhos territórios do império português. (idem: 592)

Se para Beatriz Sarlo a ordem imposta do shopping center quer transmitir o fato de "a ordem do mercado [ser] mais eficaz do que a ordem pública; daí a dinâmica da mercadoria ser mais forte que o Estado" (2014: 6), no caso do Centro Comercial da Mouraria, a sua desordem e a pluralidade infinita de seus produtos exóticos querem propiciar para o visitante e cliente uma experiência ucrônica de poder passear pelas rotas comerciais do antigo império colonial. Rotas das quais, através da lógica do consumo - de poder adquirir facilmente produtos oriundos de todos os cantos do mundo, de poder levar para casa uma porção desejada de Índia ou de África é retirada qualquer referência à violência e ao sangue derramado.

Obliterando qualquer forma de violência subjacente aos encontros lisboetas, assim como as ações "multiculturais" do poder público em Lisboa, essa produção literária desenha também um emaranhado urbano exclusivamente restrito ao centro da cidade, marcado, portanto, pela sistemática ausência das periferias que, de norte a sul, rodeiam a capital portuguesa. Pode ser considerado um caso emblemático dessas dinâmicas também a coletânea Guia Ler e Ver Lisboa (2016), cuja publicação foi promovida sempre pela Câmara Municipal de Lisboa e que reúne a contribuição artística e literária de vinte escritores e vinte ilustradores. A obra foi amplamente investigada, com olhar crítico, por Patrícia Marinho Ferreira (2020), num ensaio através do qual a autora interroga justamente as ausências - privilegiando mais o fator humano e menos o 
estritamente espacial - e as faltas dessa construção da capital portuguesa promovida pelo poder público. De acordo com Martinho Ferreira:

While Lisbon Tales and Trails does not claim to be a comprehensive collection of all of the ways the city can be perceived, there are nonetheless significant features of the Lisbon ethnoscape that remain invisible or insufficiently represented in this collection of short stories-features that are necessary to consider if one wishes to have an adequate understanding of the city's social dynamics as a whole. [...] In the first place, there are the tens of thousands of commuters who pour into the Lisbon city center every day to work. In fact, even as Lisbon Tales and Trails encourages the reader to walk the most unexpected paths in Lisbon, the contributors consistently neglect the outskirts of the Portuguese capital, which are an essential part of the city's life. [...] It is also striking that most of the writers in Lisbon Tales and Trails largely ignore migrant experiences, specifically those of Lusophone African origin and their descendants. (2020: 94-95)

[Embora Guia Ler e Ver Lisboa não pretenda ser uma coleção abrangente sobre todas as formas como a cidade pode ser percebida, há, no entanto, algumas características significativas da ethnoscape de Lisboa que permanecem invisíveis ou insuficientemente representadas nesta coleção de contos - características que são necessárias para considerar, caso se deseje ter uma compreensão adequada da dinâmica social da cidade como um todo. [...] Em primeiro lugar, são as dezenas de milhares de trabalhadores que se deslocam diariamente ao centro da cidade de Lisboa para trabalhar. Na verdade, mesmo que Guia Ler e Ver Lisboa encoraje o leitor a trilhar os caminhos mais inesperados de Lisboa, os colaboradores sempre negligenciam os arredores da capital portuguesa, que são uma parte essencial da vida da cidade. [...] Também é surpreendente que a maioria dos escritores de Guia Ler e Ver Lisboa ignorem amplamente as experiências dos migrantes, especificamente aqueles originários da África Lusofona e de seus descendentes.]

No que diz respeito à paisagem humana, uma eloquente exceção nesse roteiro lisboeta é a contribuição do escritor angolano Kalaf Epalanga, que conduz o leitor numa flânerie pós-imperial ao longo dos espaços marcados pela diferença étnico-racial, a já citada Avenida Almirante Reis. Como afirma Patrícia Marinho Ferreira, a visão da cidade construída pelo passeio de Epalanga numa das áreas mais multiculturais de Lisboa manifesta uma clara abertura às diferenças étnicas, sublinhando seja os vínculos com o passado colonial seja as violências intrínsecas à condição de migrante contemporâneo:

At the end of the narrative, any account of cultural homogeneity seems an illusion. One can claim that the celebration of Lisbon's multiculturalism in "From Avenida Almirante Reis to Areeiro" does not hide social tensions, which are endemic to a society that for centuries has defined itself in relation to its empire and still looks to understand its postcolonial reality. 
[No final da narrativa, qualquer relato de homogeneidade cultural parece uma ilusão. Pode-se afirmar que a celebração do multiculturalismo lisboeta em "Da Avenida Almirante Reis ao Areeiro" não esconde tensões sociais endêmicas a uma sociedade que há séculos se define em relação ao seu império e ainda busca entender sua realidade pós-colonial.] (idem: 98)

Nesse sentido, a contribuição de Kalaf Epalanga manifesta total coerência com outros textos do autor, incluindo tanto as publicações em jornais e revistas - veja-se, apenas como exemplo o texto "Entre a Alameda D. Afonso Henriques e a Rua de Angola", publicado na revista independente Rede Angola, ${ }^{5}$ um esboço do que será publicado em Guia Ler e Ver Lisboa - tanto as em livros, como em O Angolano que comprou Lisboa (por metade do preço) (2014), e Também os brancos sabem dançar (2017).

Portanto, se de um lado certas estratégias de mercado pretendem fazer de Lisboa a capital exótica da Europa, pacificando os conflitos internos à capital portuguesa, por outro lado desenvolveram-se, principalmente a partir da segunda década do século XXI, algumas produções literárias que descrevem e interrogam o espaço urbano lisboeta a partir justamente dos conflitos cotidianos sobre os quais assentam tanto as vivências coletivas tanto as (im)possibilidades de inserção social de sujeitos deslocados, frequentemente oriundos das ex-colônias africanas. De fato, a "literatura contemporânea de autoria negra em Portugal", de acordo com a denominação proposta por Rosangela Sarteschi (2019) na sua rica cartografia dos autores negros em terras lusas, ou literatura "Afropeia" em português, retomando uma expressão (Afropeans) ${ }^{6}$ proveniente dos contextos anglófonos, apesar de muitas vezes à margem do grande mercado editorial, como evidencia Emerson da Cruz Inácio (2019), aparece como um terreno de investigação fértil, pelas suas inovações estético-formais, assim como pelas demandas políticas veiculadas através da escrita literária.

É dentro dessas escritas negras em Portugal que se insere Djaimilia Pereira de Almeida, autora nascida em Angola, mas que desde nova habita as ruas de Lisboa, cujo romance Luanda, Lisboa Paraíso (2018) - publicado, nesse caso, dentro do grande circuito editorial - permite um amplo debate em torno da inserção subalterna dos africanos em Portugal, evidenciando as tensões e as violências subjacentes ao multiculturalismo da capital como persistência das dinâmicas coloniais na contemporaneidade urbana.

Com essa obra, Djaimilia Pereira de Almeida volta, de fato, às geografias encenadas no seu primeiro romance, Esse cabelo, a tragicomédia de um cabelo crespo que cruza fronteiras (2017): "a experiência do afastamento de Angola, por conseguinte da África, em meados da década de 1980 no contexto da pós-independência, com a nação massacrada pela guerra civil, é a mesma que a escritora já abordara em seu primeiro livro [...]." (Lima 2020). Embora Esse cabelo, a tragicomédia de um cabelo crespo que cruza fronteiras elabore ficcionalmente temáticas vinculadas ao corpo feminino e à identidade de gênero (Sousa, 2017) ausentes em Luanda, Lisboa, Paraíso, este último pode ser lido como um outro desdobramento possível do primeiro romance, no qual a autora abandona o relato em primeira pessoa, para narrar com uma ironia desencantada as peripécias migrantes de Cartola e Aquiles, pai e filho que por 
razões de saúde - Aquiles precisará passar por uma cirurgia ao calcanhar esquerdo nascido malformado -, na metade da década de oitenta deixam Angola e vêm para Portugal.

A figura de Cartola, central no romance juntamente com Aquiles, merece uma atenção particular pois se trata de uma figura inédita dentro do amplo corpus de obras que encenam as viagens das antigas colônias africanas, rumo a Portugal, após as independências: já não um retornado, ${ }^{7}$ isto é, um colonizador de volta para a antiga metrópole, mas um assimilado ${ }^{8}$ que, apesar de se sentir/imaginar português, nunca gozou dos plenos direitos de cidadania - aos olhos do filho Aquiles, "Um 'portuguesão' dispensado pelo império a que jurara obediência" (Almeida 2018: 42).

A figura de Cartola aparece, portanto, profundamente complexa, pois, se por um lado, a assimilação dependia da imposição e da absorção, violenta, do modelo europeu por parte do colonizado, "lo spodestamento di sé nell'intimo del santuário anima/corpo [a expropriação de si mesmo dentro do santuário de alma/corpo]" (Gnisci 2003: 41) retomando as palavras de Armando Gnisci, por outro lado, este processo só permitia a manutenção legal da inferioridade social, juridicamente constituída (Meneses 2010). Ao passar da condição de assimilado na colônia para migrante na antiga metrópole do império, Cartola conserva a mesma subalternidade em termos de direitos. Em Lisboa, ele e Aquiles são de fato "humanos espectrais, desprovidos de peso ontológico [...] produzidos como sem-estado, ao mesmo tempo em que são alijados dos modos jurídicos de pertencimento. [...] De diferentes maneiras, eles, significativamente, se encontram circunscritos dentro da polis como seu exterior" (Butler/Spivak 2018: 25). As palavras de Judith Butler aqui citadas referem-se, de forma abrangente, aos sujeitos que por "idade, gênero, raça, nacionalidade e situação laboral" (ibidem) encontram-se à margem do Estado de Direito, sem nenhuma proteção legal. Essa condição é, efetivamente, vivenciada por Cartola e Aquiles em Lisboa e, apesar da diversa configuração política do espaço colonial - um espaço de fronteira, de acordo com Achille Mbembe (2016) -, pode ser apropriada também para os antigos assimilados.

Como para a grande parte dos migrantes contemporâneos, a cidadania almejada torna-se, pouco a pouco, no decorrer do romance, um sonho distante no qual afogar as mágoas de ter-se sentido, um dia, um português em Angola. O migrante de hoje e o assimilado de ontem estão entrelaçados numa condição de profundo estranhamento:

Confiou o pedido da nacionalidade portuguesa a Barbosa da Cunha passando-lhe para a mão uma pasta com papelada que não voltou a ver. Pelo menos uma vez por ano, assegurava a Aquiles que os documentos estavam para sair. 'Vai sair, menino Aquiles, agora, se me faz esse favor, olhos na ortografia que sem ortografia isso não anda para a frente!', dizia sem olhar para o filho, como quem, apesar do tom de gozo, falasse de um parente afastado. Não contava a ninguém que não sabia em que pé estava o processo, de que o obstetra pouco ou nada falava. Vivia com medo da Polícia, de uma rusga. Planeava fazer-se de morto caso o abordassem. Parecia pensar que um dia lhe bateriam à porta e lhe diriam que estava tudo tratado, que era enfim português, direito que julgava pertencer-lhe. Não sabia ele conjugar o gerundivo e a origem etimológica da palavra «Tejo»? [...] Não escolhera já o seu talhão no Cemitério dos Prazeres, para onde se 
esquivava a entoar cânticos fúnebres em kikongo enquanto admirava os jazigos de família? Não se arrepiava ao ouvir o hino de Portugal e sabia de cor a primeira estrofe dos Lusíadas? (Almeida 2018: 88-89)

Sem documentos para tentar moldar a permanencia na Europa, o destino de Cartola e Aquiles em Lisboa será o mesmo dos tantos migrantes no já citado filme de Sérgio Tréfaut: entregues à expertise e a crueldade dos aliciadores que, nas ruas de Campo Grande, de madrugada, oferecem trabalhos exploratórios na área da construção civil. A metamorfose de Cartola, de assistente do obstetra Barbosa da Cunha em Angola para servente de pedreiro em Lisboa, passa também pelo corpo, "as mãos de Cartola não estavam na mesma. Olhava para elas como se pertencessem a outra pessoa. Não sabia dizer com que homem as havia trocado nem recordava quando se dera esse transplante" (idem: 59). Aos olhos da filha Justina, em Lisboa para uma vista ao pai e ao irmão após sete anos de afastamento, as alterações no corpo aparecem evidentes:

As mãos dele tinham mudado, assim como a amplitude dos braços, que ela reparou estarem robustos. [...] Não eram as mãos do pai de outrora, cujas unhas ela costumava limar ao domingo à tarde, ajoelhada aos pés da poltrona dele. Também a voz de Cartola lhe pareceu estranha. Dava ideia de não sair da sua boca, como num filme mal dobrado. A cara mexia, a cabeça movia-se, engasgava-se, gargalhava, mas nenhum movimento correspondia à pronúncia que a filha ouvia do banco de trás. Os olhos do pai também lhe pareceram diferentes, mais escuros do que se lembrava. (idem: 125)

Assim como as ambições, os desejos e até o próprio corpo de Cartola, uma das metamorfoses mais claras no interior do romance envolve também a cidade de Lisboa, que ganha feições diferentes no decorrer da narração. Luanda, Lisboa, Paraíso divide-se em três partes, não homogêneas, que acompanham as geografias do título: a primeira passa-se em Angola, a segunda em Lisboa, com Cartola e Aquiles hospedes na decadente Pensão Covilhã, e a terceira na Quinta do Paraíso, bairro fictício, periférico, ao redor da capital portuguesa. Ainda em Angola, a capital ibérica tem a aparência de um sonho, a cidade do progresso que espera o seu filho, Cartola, de volta para casa - uma casa na qual jamais tinha estado antes. Lê-se no princípio do romance:

Sentado num banco, Cartola enrolava cigarros à janela. Repetia quantos nomes de ruas lisboetas conhecia e afinava a pronúncia como se falasse pela primeira vez. «António Augusto Aguiar, efectivamente, meu caro, seguimos para a António Augusto Aguiar, faz favor», dizia a um imaginário condutor de táxi, e, mesmo que de olhos no prédio em frente, cortava a capital no lugar do morto de um Mercedes-Benz. Chegaria velho à metrópole cuja rapidez o assustava à partida. 'Sigamos para Sete-Rios, faz favor', mas o taxista gramático respondia, com uma tossidela cortante, que não tinha troco de quinhentos escudos. Lisboa esperou que ele se rendesse para o receber. Se finalmente viajava para a cidade do progresso, sabia que recolhia a ela como um soldado ferido volta a casa. (idem: 23-24)

Já em Lisboa, a imagem do progresso e as ambições da ascensão social não demoram em desaparecer. De fato, a segunda parte do romance é o lento caminho para a resignação com- 
pleta dos protagonistas. A decepção, porém, afeta pai e filho já nas primeiras visões da cidade, ainda "dentro de um táxi, com o olhar curioso de duas crianças, viram Lisboa pela primeira vez. Pareceu-lhes pequena e escura" (idem: 33). A sensação dos primeiros momentos torna-se mais aguda, na medida em que aumenta a experiência dos dois em Portugal. Se a perda da esperança na cidadania portuguesa e o trabalho na construção civil transformaram Cartola num homem irreconhecível aos seus próprios olhos, a permanência na cidade afetou também Aquiles, que viu a sua adolescência passar entre camas de hospitais e cirurgias que não tiveram o sucesso desejado: "a sua adolescência foi uma brisa que percorreu Lisboa ao fim da tarde e agitou apenas uma folha. Quando deu por si, era um homem e tinha o pai às costas. Fala-se da luz de Lisboa, mas ela não iluminou Aquiles" (idem: 77).

Esse movimento encenado por Almeida, com a vivência na cidade de Lisboa que desconstrói qualquer imaginário mítico sobre o espaço metropolitano, apesar de pouco frequente, não é certamente inédito na cultura portuguesa. Nesse sentido, o romance dialoga tanto com o filme Lisboetas tanto com um outro romance sobre fluxos atlânticos, de Luanda para Lisboa: O retorno (2011), de Dulce Maria Cardoso. No primeiro caso, ao acompanhar os passos de uma mulher chinesa, uma voz em off descreve Lisboa e, metonimicamente, Portugal, como o fim do mundo. Na voz de uma mãe que chama a filha pelo viés dos sonhos, vê-se uma Lisboa que é apenas o cabo final da Eurásia. Assim, às memórias de uma cidade outrora centro de um império tão vasto quanto o espaço do Minho a Timor, às perspectivas de uma Lisboa "encruzilhada de mundos", essencialmente multiétnica, substitui-se a imagem real de uma cidade pobre, longínqua, situada onde a terra acaba. Em 0 retorno, romance que encena as tensões subjacentes à descolonização de Angola e aos processos de democratização de Portugal após o 25 de Abril, pelo olhar de uma família de retornados, a oposição entre imaginário mítico e realidade concreta também se impõe aos leitores. Como em Luanda, Lisboa, Paraíso, a chegada de táxi decepciona as expectativas:

A metrópole tem de ser como este hotel que até no elevador tem uma banqueta forrada a veludo. Portugal não é um país pequeno, era o que estava escrito no mapa da escola, Portugal não é um país pequeno, é um império do Minho a Timor. A metrópole não pode ser como hoje a vimos no caminho que o táxi fez, ninguém nos ia obrigar hinos aos sábados de manhã se a metrópole fosse tão acanhada e suja, com ruas tão estreitas onde parece que nem cabemos. (Cardoso 2011: 83)

Abandonada qualquer ilusão e qualquer esperança de inserção social, a última parte do romance de Djaimilia Pereira de Almeida desenha a luta para sobrevivência num lugar hostil, marcado pela precariedade, e as frágeis tentativas, tragicamente frustradas, de criação de laços de pertencimento. Estranhos aos lugares, a instauração desses vínculos passa pelo campo do afeto, envolvendo Cartola, Aquiles e a pequena comunidade da Quinta do Paraíso - aonde ninguém vai de visita, como se lê no romance - representada por Pepe, um galego que viera ainda bebê para Portugal, seu filho Amândio, que como no caso da dupla angolana mantém com o pai uma relação de incomunicabilidade, Iuri, uma criança do bairro que ganhou a con- 
sideração de Pepe, e Tristão, o cão do galego. Entre esse pequeno grupo instituem-se práticas de ajuda e assistência mútua que parecem propor a possibilidade de existência de uma comunidade - no sentido etimológico do termo communitas, estritamente vinculado ao munus, proposto por Roberto Esposito (2006) - que não passa obrigatoriamente pela compensação material ou pela contrapartida. O espaço da Quinta do Paraíso é, desta forma, antagônico ao da capital portuguesa, no qual Cartola e Aquiles são justamente "humanos espectrais" explorados nos canteiros da construção civil, ou considerados corpos perturbadores na cidade:

Aquiles não contou ao pai que viu o Dr. Barbosa da Cunha nos Restauradores sentado numa esplanada com uma senhora. [...] $\mathrm{O}$ rapaz aproximou-se da mesa e cumprimentou o doutor. 'Não tenho trocos, desculpe lá.' 'Dr. Barbosa da Cunha, sou eu, o Aquiles, filho do Dr. Cartola de Sousa, de Moçâmedes.' 'Desculpe, homem, já disse que não tenho nada. Ponha-se a andar, se faz favor.' E a senhora, incomodada com o pedinte educado, abriu a carteira das moedas e estendeu-lhe sem querer um botão de madre-pérola que Aquiles, com desdém, deitou para uma fonte ao passar pelo Rossio. (Almeida 2018:162)

O final trágico do romance inibe qualquer projeção romântica sobre a vivência periférica na capital portuguesa. Os últimos capítulos de Luanda, Lisboa, Paraíso revelam a fragilidade e a impossibilidade das tentativas de pertencimento num espaço marcado pela falta e pela carência. Contrariamente à imagem pacificadora, luso-tropicalista, proposta pelo poder publico, as "encruzilhadas de mundos" que compõem o tecido social lisboeta se dão através de múltiplas formas de violência.

A cidade torna-se então teatro de "culturas em colisão" (Mbembe 2015), onde a instrumentalização do corpo do Outro como mão de obra barata - Cartola e Aquiles, sem documentos, nos canteiros da construção civil - se articula à reificação e capitalização da diferença, operadas pelo poder público no centro da cidade. Nesse sentido, o romance de Djaimilia Pereira de Almeida, ao desenhar uma visão de Lisboa dissonante em relação ao imaginário hegemônico imposto, evidencia também as continuidades e persistências dos paradigmas coloniais na contemporaneidade urbana lisboeta.

\section{NOTAS}

* Luca Fazzini é pesquisador de Pós-doutorado em Estudos Comparados de Literaturas de Língua Portuguesa (USP). Mestre em Estudos Comparatistas pela Universidade de Lisboa (UL) e doutor em Literatura, Cultura e Contemporaneidade pela Pontifícia Universidade Católica do Rio de Janeiro (PUC-Rio, é autor de Versões do Horror: Guerra Testemunho no Romance Português e Italiano Contemporâneo (Lisboa/Colibri) e de diversos outros ensaios. 


\section{Cadernos de Literatura Comparada}

Visões de Lisboa em dissonância

${ }^{1}$ Trata-se dos contos: "Durante a construção da Muralha da China", em Narrativas do espólio (2002), e "Uma folha antiga", in Um médico Rural (1999).

${ }^{2}$ A referência ao conceito de Arjun Appadurai é retirada do estudo de Patrícia Marinho Ferreira (2020).

${ }^{3}$ Doravante, sempre que as referências forem direcionadas ao citado romance, a expressão virá em itálico (O Magriço). Quando não grafada assim, ela se refere ao protagonista homônimo (Álvaro Gonçalves Coutinho - o Magriço), personagem principal da obra em análise.

${ }^{3}$ Sobre as múltiplas formas de privação de direitos e violência institucional nas periferias de Lisboa, ver o estudo "Para eles, nós não somos humanos!: habitação, território e a monitorização de violências racializadas em Portugal" (2019), de Ana Rita Alves.

4 Sobre o vínculo entre indústria cultural, mercado e processos de hibridização do Eu, veja-se o capítulo "Ascensão e ascensão da plasticidade mercantil do corpo", de Vladimir Safatle (2016: 135-158). Citando o filósofo: "Estaríamos agora diante de uma indústria cultural que incita a reconfiguração contínua e a construção performativa de identidades. Na verdade, o setor mais avançado da cultura do consumo não forneceria mais para o Eu a positividade de modelos estáticos de identificação. Ele forneceria apenas a forma vazia da reconfiguração contínua de si que parece aceitar, dissolver e passar por todos os conteúdos. Isso poderia nos explicar por que teríamos cada vez menos a necessidade de padrões claros de conformação do corpo e ideias sociais" (Safatle 2016: 149).

${ }^{5}$ Disponível em: http://www.redeangola.info/opiniao/entre-alameda-d-afonso-henriques-e-rua-de-angola/. Ultimo acesso: $27 / 12 / 2020$.

${ }^{6}$ A expressão Afropeans, proposta por Johny Pitts em Afropean: Notes from Black Europe, aparece particularmente pertinente para pensar a "dupla consciência" (Gilroy 2012) - africana e, ao mesmo tempo, europeia - de certas subjetividades espalhadas pelos países do velho continente. Retomando a provocação de Antônio Pinto Ribeiro e Margarida Calafate Ribeiro: "Será cedo ainda para o confirmar, mas o melhor da Europa em potência é o facto cultural que toma o Afropeísmo - a conjugação das múltiplas identidades em formação, híbridas com certeza - inomináveis como já dissemos. O Afropeísmo, ao contrário de outras propostas ideológicas de exclusão, é uma situação de facto, uma interculturalidade presente onde memórias diferentes com expressões e impactos diferentes no mesmo ou em múltiplos sujeitos desafiam-nos para uma escolha inadiável: vamos construir ou destruir muros?" (2020: 4). Veja-se também o artigo: "Notes on imagining Afropea" (2015), de Charl Landvreugd.

${ }^{7}$ Sobre a figura do retornado na literatura portuguesa contemporânea, assim como os seus mais recentes desdobramentos literários, veja-se Margarida Calafate Ribeiro (2012).

${ }^{8} \mathrm{O}$ "Estatuto Político, Civil e Criminal dos Indígenas das colónias portuguesas de África", também conhecido como Estatuto do Indigenato, aprovado pelo Decreto n. ${ }^{0} 16.473$ de 6 de fevereiro de 1929, institui a categoria jurídica dos chamados assimilados. Citando Maria Paula G. Meneses: "Os assimilados - a terceira categoria presente no espaço colonial - encontram também expressão neste estatuto, que estipulava em detalhe as condições de acesso ao mesmo. Nos termos do Estatuto, assimilados eram os antigos indígenas que haviam adquirido a cidadania portuguesa, após provarem satisfazer cumulativamente os requisitos que transitavam do passado recente: a) ter mais de 18 anos; b) falar correctamente a língua portuguesa; c) exercer profissão, arte ou ofício de que aufira rendimento necessário para o sustento próprio e das pessoas de família a seu cargo, ou possuir bens suficientes para o mesmo fim; d) ter bom comportamento e ter adquirido a ilustração e os hábitos pressupostos para a integral aplicação do direito público e privado dos cidadãos portugueses; e) não ter sido notado como refractário ao serviço militar nem dado como desertor" (2010: 78). 


\section{Bibliografia}

Agualusa, José Eduardo (1999), Lisboa cidade de exílios. O mundo em Lisboa, Lisboa, CML.

Almeida, Djaimilia Pereira de (2017), Esse cabelo. A tragicomédia de um cabelo crespo que cruza fronteiras, Rio de Janeiro, Leya.

-- (2018) Luanda, Lisboa, Paraíso. Lisboa, Companhia das letras.

Almeida, Miguel Vale de (2006), "Comentário", in Portugal não é um país pequeno: contar o império na pós-colonialidade, Lisboa, Edições Cotovia, 359-367.

Alves, Ana Rita (2019), "'Para eles, nós não somos humanos!': habitação, território e a monitorização de violências racializadas em Portugal", Direito e práxis, Vol. 10, n.3, Rio de Janeiro, 2068-2096.

Appadurai, Arjun (1991), "Global Ethnoscapes: Notes and Queries for a Transnational Anthropology", in Interventions: Anthropologies of the Present. School of American Research, Santa Fé, School of American Research, 191-210.

Balibar, Étienne (2019), Il fantasma del corpo estraneo: per un diritto internazionale dell'ospitalità, Roma, Castelvecchi.

Butler, Judith/ Spivak, Gayatri Chakravorty (2018), Quem canta o estado nação? Língua, política, pertencimento, Brasília, Editora UnB.

Cardoso, Dulce Maria (2011), O retorno, Lisboa, Tinta-da-China.

Derrida, Jacques (1995), o outro cabo, Coimbra, A Mar Arte.

Esposito, Roberto (2006), Communitas. Origine e destino della comunità, Torino, Einaudi.

Gilroy, Paul (2004), After empire: melancholia or convivial culture?, Oxfordshire, Routledge.

-- (2012), O Atlântico negro: modernidade e dupla consciência, Rio de Janeiro, Editora 34.

Ferreira, Patrícia Martinho (2020), "Imperial Debris: Reflections on the Lisbon Cityscape in

Contemporary Portuguese Fiction", Journal of Lusophone Studies, n. 5.2, American Portuguese Studies Association, 93-110.

Guia ler e ver Lisboa (2016), Lisboa, EGEAC.

Inácio, Emerson da Cruz (2019), "Novas perspectivas para o Comparatismo Literário de Língua Portuguesa: as séries afrodescendentes", Revista Crioula, n.23, USP, 12-33.

Landvreugd, Charl (2015), "Notes on imagining Afropea", Open Arts Journal, Issue 5, Rotterdham, 39-52.

Lima, Norma Sueli Rosa (2020), "Esse cabelo em Luanda, Lisboa, Paraíso: Djaimilia Pereira de Almeida e a experiência do desenraizamento na tentativa de integração", Convergência Lusíada, v. 31, n. 43, Real Gabinete de Literatura Portuguesa, 12-24.

Malheiros, Jorge Macaísta (1997), Imigrantes na região de Lisboa. Os anos da mudança, Lisboa, Edições Colibri.

Mbembe, Achille (2015), "Afropolitanismo", Áskesis, v.4, n.2, UFSCar, 68-71.

-- (2016), "Necropolítica", Arte \& Ensino, n. 23, UFRJ, 123-151.

Mapril. José (2013). "Um lugar estrutural? Legados coloniais e migrações globais numa rua em Lisboa", in Cidade e império: dinâmicas coloniais e reconfigurações pós-coloniais, Lisboa, 
Edições 70, 503-525.

Meneses, Maria Paula G. (2010), “O 'indigena' africano e o colono 'europeu': a construção da diferença por processos legais", E-Cadernos, n.7, CES, 68-93.

Moretti, Franco (2017), Il borghese. Tra storia e Letteratura, Torino, Einaudi.

Oliveira, Nuno (2013), "Lisboa redescobre-se. A governança da diversidade cultural na cidade pós-colonial. A scenescape da Mouraria", in Cidade e império: dinâmicas coloniais e reconfigurações pós-coloniais, Lisboa, Edições 70, 557-603.

Pelbart, Peter Pál (2003), Vida Capital: Ensaios de biopolítica, São Paulo, Ed. Iluminuras.

Peralta, Elsa (2013). "A composição de um complexo de memória: o caso de Belém, Lisboa", in Cidade e império: dinâmicas coloniais e reconfigurações pós-coloniais. Lisboa, Edições 70, 361-415.

Pitts, Johny (2019), Afropean: Notes from Black Europe, London, Allen Lane.

Ribeiro, António Pinto (2005), "Portugal contemporâneo: entre a pré-modernidade e o cosmopolitismo", in Literatura/Política/Cultura, Belo Horizonte, Editora UFMG.

Ribeiro, Margarida Calafate (2012), "O fim da história de regressos e o retorno à África: leituras da literatura contemporânea portuguesa", in Itinerâncias. Percursus e representações da pós-colonialidade, Famalição, Edições Húmus.

Ribeiro, Antônio Pinto/ Ribeiro Margarida Calafate (2020), "A Europa é só um arquipélago?", in_Memoirs, Coimbra, CES, 3-5.

Santiago, Silviano (2004), O cosmopolitismo do pobre, Belo Horizonte, Editora UFMG.

Safatle, Vladimir (2016), o circuito dos afetos: corpos políticos e o fim do indivíduo, Belo Horizonte, Autêntica Editora.

Sarteschi, Rosangela (2019), "Literatura de autoria negra em Portugal: impasses e tensões", Via Atlântica, n. 36, USP, 283-304

Sousa, Sandra (2017), "A descoberta de uma identidade pós-colonial em Esse Cabelo, de Djaimilia Pereira de Almeida", Abril, v. 9, n.18, UFF, 57-68.

\section{Filmes citados}

Sérgio Tréfaut, Lisboetas, Portugal, 2004, 105'. 